\title{
Different temporal and spatial expression of two hydrophobin-encoding genes of the edible mushroom Agaricus bisporus
}

\author{
Piet W. J. De Groot, ${ }^{1}+$ Robert T. P. Roeven, ${ }^{2}$ Leo J. L. D. Van Griensven, ${ }^{2}$ \\ Jaap Visser ${ }^{1}$ and Peter J. Schaap ${ }^{1}$
}

1 Section Molecular Genetics of Industrial Microorganisms, Wageningen Agricultural University. Dreijenlaan 2, NL-6703 HA, Wageningen,

The Netherlands

2 Mushroom Experimental Station, PO Box 6042 NL-5960 AA, Horst, The Netherlands

\author{
Author for correspondence: Peter Schaap. Tel: +31317 485142. Fax: + 31317484011. \\ e-mail: Peter.Schaap@algemeen.mgim.wau.nl
}

In a search for genes that are only expressed in fruit bodies of the basidiomycete Agaricus bisporus, two cDNAs, hypA and hypB that encode hydrophobins have been isolated previously. In this study, the structure of hypB is resolved and it is shown that the two genes are differentially expressed, indicating that the encoded hydrophobins serve different functions in A. bisporus mushrooms. hypB encodes a polypeptide (HYPB) of 119 aa that shows little sequence identity with HYPA apart from the characteristic arrangement of eight cysteines found exclusively in hydrophobins. The temporal and spatial expression of the two hydrophobin-encoding genes during fruit body development was compared using Northern analysis and in situ hybridization. Accumulation of hypA mRNA was found in tissue fractions consisting of undifferentiated white hyphae. In situ hybridization showed that the highest hypA mRNA levels are not found in the outermost cell layers of the pileipellis but in the cell layers adjacent to that. The highest level of expression of hypB occurs early in development when the primordium differentiates into densely packed, randomly oriented cap hyphae and loosely packed, vertically oriented stipe hyphae. In mature mushrooms, a strong accumulation of hypB transcripts was found only in the transitional zone between cap and stipe tissue, demonstrating that transcription regulation of hypB is clearly distinct from hypA.

Keywords: hypA, bypB, Agaricus bisporus, fruit body development, hydrophobin

\section{INTRODUCTION}

The edible fungus Agaricus bisporus is commercially cultivated on a large scale for mushroom production. The differentiation process leading to these reproductive structures is influenced by available nutrients and abiotic factors such as temperature, humidity and the carbon dioxide concentration (Flegg \& Wood, 1985). By manipulating environmental conditions during cultivation, the onset and further development of fruit body formation can be controlled to optimize mushroom yields. At present, however, it is unclear what molecular

†Present address: Institute for Molecular Cell Biology, University of Amsterdam, Kruislaan 318, 1098 SM Amsterdam, The Netherlands.

The EMBL accession numbers for the sequences reported in this paper are $Y 15940$ and $Y 15941$ (hypB genomic and CDNA sequences, respectively) and Y15942 (sudA). mechanisms program the vegetatively growing mycelium to start differentiation.

For a better understanding of this process, we have previously isolated cDNAs specifying genes that were either strongly induced or specifically expressed in fruit bodies (De Groot et al., 1996, 1997). From various filamentous fungi, structural genes associated with cellular differentiation processes have been isolated and amongst them genes encoding hydrophobins are often found (reviewed by Wessels, 1997). Hydrophobins are small cell wall proteins of about 110 aa that have eight cysteine residues at characteristic positions, a signal sequence for secretion and a specific hydrophobicity pattern. By interfacial self-assembly, hydrophobins form amphipathic films that provide aerial structures with a hydrophobic surface. Hydrophobin aggregates are normally not dissolved in solutions of $2 \%$ SDS but can be 
dissociated into monomers using trifluoroacetic acid or formic acid (Wessels, 1997).

One of the fruit-body-specific genes isolated from $A$. bisporus, bypA, was previously shown to encode a hydrophobin. Accumulation of $b y p A$ mRNA was found in the pileipellis (peel) of mushroom caps, constituting more than $60 \%$ of the total mRNA population in that tissue. Treatment of pileipellis tissue with SDS followed by dissociation of the hydrophobin aggregates by trifluoroacetic acid extraction resulted in isolation of the corresponding HYPA protein (De Groot et al., 1996). The self-assembling nature of this protein was shown by in vitro studies, in which HYPA (also named ABH1) protein extracts adhered strongly to hydrophobic surfaces, thereby forming hot-SDS-resistant monolayers (Lugones et al., 1996; Gunning et al., 1998) as has also been shown for the well-studied Sc3p hydrophobin from the basidiomycete Schizophyllum commune (Wösten et al., 1994b). HYPA was therefore proposed to be the major constituent of the protective hydrophobic layer surrounding mushroom caps.

In addition to byp $A$, other hydrophobin-encoding genes were discovered in A. bisporus. The genomic region immediately downstream of bypA contains bypC, a fruit-body-specific gene for which only low levels of expression were detected (De Groot et al., 1996). hypC and its immediate surroundings are $84 \%$ identical at the nucleotide level to the bypA region and $b y p C$ is therefore probably the result of a duplication event (De Groot $e t$ al., 1996; Lugones et al., 1996). Recently, a hydrophobin (ABH3) specifically secreted by vegetatively growing hyphae of A. bisporus was isolated (Lugones et al., 1998).

In an effort to elucidate the function of more fruit-bodyspecific genes of $A$. bisporus, we analysed the sequence of a number of the corresponding cDNAs. In this study, we show that pDG47 specifies a protein that also has all the characteristics typical of fungal hydrophobins but is distinct from HYPA. This hydrophobin was designated HYPB. Because a workable transformation system is not yet available for A. bisporus, the regulation of the two genes was compared by performing detailed analyses of temporal and spatial expression of both hydrophobins using conventional Northern analysis and in situ hybridization. We show that bypA and bypB are differentially regulated and probably serve disparate functions in developing mushrooms.

\section{METHODS}

A. bisporus strains and culture conditions. Cultivated Agaricus bisporus strain Horst U1 and one of its homokaryotic constituents, H39, were grown on cellophane sheets in Petri dishes containing DT80 medium (Sonnenberg et al., 1988) supplemented with either $3 \%(\mathrm{w} / \mathrm{v})$ glucose or $7 \cdot 5 \%(\mathrm{w} / \mathrm{v})$ powdered and sterilized compost (Van Gils, 1988) and solidified with $1.5 \%(\mathrm{w} / \mathrm{v})$ agar. Colonies were collected after $10 \mathrm{~d}$ growth at $24^{\circ} \mathrm{C}$ and frozen in liquid nitrogen.

A. bisporus Horst U1 fruit bodies were obtained using a $10 \mathrm{~d}$ flushing cycle (Van Gils, 1988). Primordia and mushrooms were harvested from the first appearance of fruit body initials ( $5 \mathrm{~d}$ after fruit body initiation) until spore-bearing mature mushrooms developed ( $10 \mathrm{~d}$ after fruit body initiation). Some mature mushrooms were separated into different fruit body parts before freezing in liquid nitrogen.

Escherichia coli strains, recombinant DNA techniques and enzymes. E. coli strain LE392 (Promega) was used for phage amplification and $\lambda$ DNA isolation. E. coli DH5 $\alpha$ (BRL) was used for plasmid transformation and propagation. Standard DNA manipulations were carried out as described by Sambrook et al. (1989). Restriction enzymes and other enzymes used for DNA manipulations were purchased from BRL and used according to the supplier's instructions. Plasmid pUC19 (Yanisch-Perron et al., 1985) was used as cloning vector for genomic DNA fragments. Cloned hybridizing fragments and cDNA clones were sequenced by the method of Sanger et al. (1977) using a Thermo Sequenase fluorescent labelled primer cycle sequencing kit with 7-deaza-dGTP (Amersham) and an ALF automated sequencer (Pharmacia).

Isolation of total genomic DNA, Southern blot analysis and cloning of the genomic sequence of hypB. For Southern analysis, total DNA of strain $\mathrm{H} 39$ was isolated according to the method of De Graaff et al. (1988), digested with various restriction enzymes, separated on $0.8 \%$ agarose gels and transferred onto Hybond- $\mathrm{N}$ membranes (Amersham). The membranes were hybridized overnight at $65^{\circ} \mathrm{C}$ by standard methods with a bypB cDNA probe labelled with $\left[\alpha^{32} \mathrm{P}\right] \mathrm{dATP}$ by random priming (Feinberg \& Vogelstein, 1983). Cloning and selection of hypB cDNA plasmid pDG47 has been described by De Groot et al. (1996). Genomic sequences of by $p B$ were obtained by screening a $\lambda$ EMBL3 genomic library of $A$. bisporus strain $\mathrm{H} 39$ by standard methods using the bypB cDNA probe. Seven $\lambda$ clones were isolated of which four comprised the complete $h y p B$ gene and surrounding regions. Relevant parts of one of these $\lambda$ clones were subcloned and sequenced.

Nucleotide and protein sequence comparisons. Database searches were performed with the University of Wisconsin Genetics Computer Group (GCG) sequence analysis software package. Homology calculations and amino acid alignments were made by using the GCG programs BESTFIT, PRETTY and PILEUP (Devereux et al., 1984). Hydrophobicity plots were generated with the program DNA Strider Version 1.1 (Marck, 1988) based on the Kyte-Doolittle algorithm with a window size of seven (Kyte \& Doolittle, 1982).

Total RNA isolation, Northern analysis and primer extension. Total RNA for Northern analysis was isolated from fruit body and mycelium samples using TRIzol reagent (BRL). The concentration of the RNA samples was determined spectrophotometrically and equal amounts of RNA were denatured in $10 \times$ SSC $(1 \times$ SSC is $0 \cdot 15 \mathrm{M} \mathrm{NaCl}, 0.015 \mathrm{M}$ trisodium citrate, $\mathrm{pH} 7 \cdot 0$ ), $6.15 \mathrm{M}$ formaldehyde and spotted on Hybond-N membrane, or denatured by glyoxal using standard techniques, separated on a $1.6 \%(\mathrm{w} / \mathrm{v})$ agarose gel and transferred to Hybond-N membrane. Hybridization of RNA blots was executed at $42{ }^{\circ} \mathrm{C}$ in standard hybridization buffer (6× SSC, $5 \times$ Denhardt's solution, $0.5 \%$ SDS and $100 \mathrm{mg}$ denatured herring sperm DNA ml ${ }^{-1}$ ), to which $10 \%(\mathrm{w} / \mathrm{v})$ dextran sulphate and $50 \%(\mathrm{v} / \mathrm{v})$ formamide were added, using byp $A$ and byp $B$ cDNAs as probes. Washing was performed at $65^{\circ} \mathrm{C}$ to a final stringency of $0 \cdot 1 \times \mathrm{SSC}, 0 \cdot 1 \% \mathrm{SDS}$. To provide a loading control, Northern blots were rehybridized with an A. bisporus 28S rDNA fragment (Schaap et al., 1996). Signal intensities were quantified by scanning the autoradiograms with an Ultroscan XL laser densitometer (LKB). Transcription 
(a)

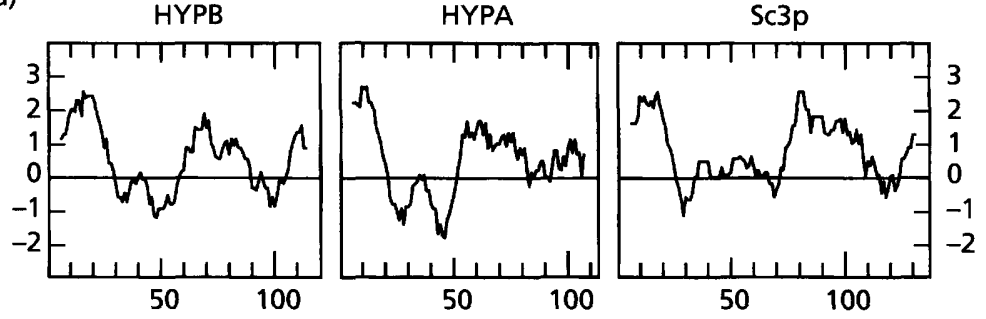

(b)

$$
\begin{array}{ll}
\text { A. bisporus } & \text { HYPB } \\
\text { A. bisporus } & \text { HYPA } \\
\text { A. bisporus } & \text { ABH3 } \\
\text { S. commune } & \text { Sc3p } \\
\text { P. tinctorius } & \text { HYdPt-1 } \\
\text { C. cinorous } & \text { CoHI } \\
\text { Consensus } &
\end{array}
$$

KOMDS . KSPOATELLTTONGL GLGVTACMTGLVGR

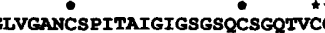

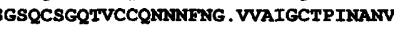
NSVQDA. SNPIVGLLA. . . GLLGIVLGPIOGLVGLTCNPISVIGG. . GNSCSSQTVCCTGNNF SGGLLVIGCSPINIDL NQVQSA. SSSPVTALL . . . GLLGIVLSDLNVLVGI SCSPLTVIGVG . GSGCSAQTVCCENTQENG . LINIGCTPINIL. NTVATSGSQSGVDELL . . . TLLGLSVP. VGTQVGASCSPISAVGTGSGAQCSGQTVCCEQNEWNG . IVNIGCMPINLNA NTVTQA . SNPVAGLLL . . GLLGIVLQDLNVLVGLTCSPISIIGLP . GNSCNAQPVCCQNNNFNG . LIAIGCTPININL --V----S-----L----GLLG--------VG--C-PI---G---G--C--Q-VCC--N-F-G----IGC-PIN---
Fig. 1. Comparison of the amino acid sequence of HYPB with other basidiomycetous class I hydrophobins. (a) Hydrophobicity plots of HYPA, HYPB and Sc3p. Points above zero on the $x$ axes indicate hydrophobic regions. (b) Alignment of the HYPB amino acid sequence to those of HYPAABH1 (De Groot et al., 1996; Lugones et al., 1996), ABH3 (Lugones et al., 1998), S. commune Sc3p (de Vocht et al., 1998), P. tinctorius HydPt-1 (Tagu et al., 1996) and $C$. cinereus $\mathrm{COH} 1$ (EMBL accession no. Y10627). The consensus sequence is composed of residues shared by at least five of the proteins. The $\mathrm{N}$-terminal amino acids of the mature HYPA, $A B H 3$ and $S c 3 p$ proteins and the putative $\mathrm{N}$-terminal end of mature HYPB are underlined. The eight conserved cysteines which were used as fixed coordinates are marked by asterisks.

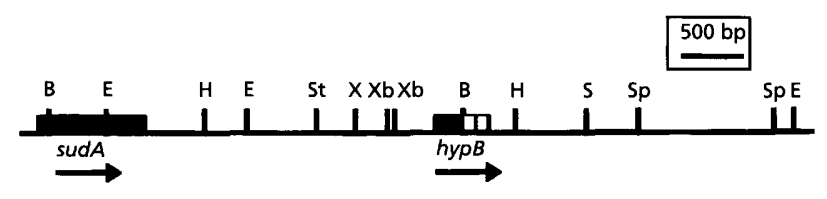

Fig. 2. Molecular map of the hyp $B$ locus. The hyp $B$ and sud $A$ coding regions are represented by black boxes and introns in the coding region of hyp $B$ are represented by open boxes. Horizontal arrows indicate the orientation of transcription of hyp $B$ and sudA. The following restriction sites are indicated: $B$, BamHI; E, EcoRl; H, HindIII; S, Sall; Sp, Sphl; St, Sstl; Xb, Xbal; $\mathrm{X}$, Xhol.

start points of $h y p B$ were determined by primer extension (Calzone et al., 1987) using RNA, treated with DNase (Promega), from pin stage mushrooms and a synthetic oligonucleotide primer positioned over the inferred translation start codon.

In situ Northern analysis. The protocol used for in situ hybridization was a modification of the method used by Bochenek \& Hirsch (1990). Fruit body tissue was fixed in $4 \%$ paraformaldehyde, $0.25 \%$ glutaraldehyde in $0.1 \mathrm{M}$ potassium phosphate buffer ( $\mathrm{pH} 7 \cdot 4)$ and for embedding we used paraffin. Subsequently, $4 \mu \mathrm{m}$ thick sections were made using a microtome. Proteinase $\mathrm{K}$ treatment was carried out at $37^{\circ} \mathrm{C}$ and acetylation was performed for $10 \mathrm{~min}$ in $0.25 \%(\mathrm{v} / \mathrm{v})$ acetic anhydride, $0 \cdot 1 \mathrm{M}$ triethanolamine $(\mathrm{pH} 8.0)$. Prehybridization buffer contained $50 \%(\mathrm{v} / \mathrm{v})$ deionized formamide, $0.3 \mathrm{M}$ $\mathrm{NaCl}, 1 \%(\mathrm{w} / \mathrm{v})$ Boehringer Mannheim blocking reagent, $0 \cdot 15 \mathrm{mg}$ yeast tRNA ml ${ }^{-1}, 1 \mathrm{mM}$ EDTA and $10 \mathrm{mM}$ Tris/HCl $(\mathrm{pH} 8 \cdot 0)$. For hybridization $\left(45^{\circ} \mathrm{C}\right)$, we used prehybridization buffer to which $5 \%(\mathrm{w} / \mathrm{v})$ dextran sulphate and $50 \mathrm{ng}$ probe per slide was added. Single-strand probes were generated from full-length $h y p A$ and $h y p B$ cDNA plasmids using T7 and T3 RNA polymerase. Plasmids were digested on one side of the insert to create a run-off reaction. The coding strands of bypA and $h y p B$ were used as negative controls. After hybridization, slides were washed in $2 \times \mathrm{SSC}$, rinsed in NTE $(0.5 \mathrm{M} \mathrm{NaCl}$, $10 \mathrm{mM}$ EDTA, $0 \cdot 1 \mathrm{M}$ Tris $/ \mathrm{HCl}, \mathrm{pH} 7 \cdot 5)$, incubated with $5 \mu \mathrm{g}$ $\mathrm{RNaseA} \mathrm{ml} l^{-1}$ at room temperature and further washed in $1 \times$ SSC and $0.5 \times$ SSC. Blocking was performed for $4 \mathrm{~h}$ with $1 \%$ $(\mathrm{w} / \mathrm{v})$ Boehringer Mannheim blocking reagent in maleate buffer $(0 \cdot 15 \mathrm{M} \mathrm{NaCl}, 0 \cdot 1 \mathrm{M}$ maleic acid, $\mathrm{pH} 7 \cdot 5)$ and overnight with $10 \%(w / v)$ BSA. Detection of hybrids was carried out with the DIG Chemiluminescent Detection Kit (Boehringer Mannheim) according to the manufacturer's instructions. Sections were viewed by light microscopy.

\section{RESULTS}

\section{hypB encodes a fruit-body-specific hydrophobin}

In a previous study, we screened a cDNA library constructed from RNA isolated from primordia for genes that were strongly expressed during fruit body development but not in vegetatively grown mycelium (De Groot et al., 1996, 1997). One of the isolated cDNA clones, pDG47, harbouring a cDNA of $481 \mathrm{bp}$, hybridized only in fruit bodies with an mRNA of $\sim 500 \mathrm{nt}$ (De Groot et al., 1997). Sequence analysis of this cDNA revealed only one large ORF which would encode a polypeptide of 119 aa with a calculated molecular mass of $11940 \mathrm{Da}$. The predicted peptide sequence contains eight cysteine residues arranged in a characteristic way found exclusively in fungal hydrophobins. The size of the encoded protein and the presence of an aliphatic sequence at the $\mathrm{N}$ terminus, which was predicted to comprise a signal sequence for secretion (Nielsen $e t$ al., 1997), further support the idea that pDG47 encodes a hydrophobin and we designated the gene hypB. Apart from the conserved spatial arrangement of the eight cysteine residues, hydrophobins generally have low levels of sequence identity. However, they display similar patterns of hydrophobicity. Based on small differences in these patterns and solubility characte- 


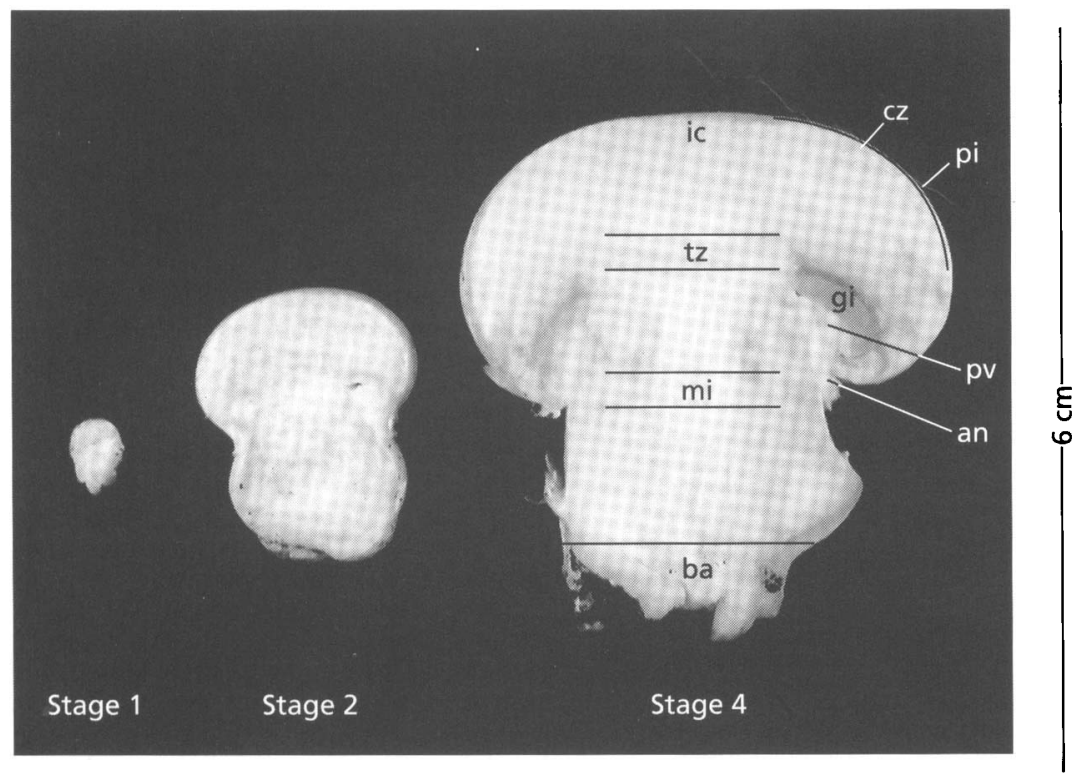

\begin{abstract}
Fig. 3. Progressive morphology of fruit bodies. Stages of development are according to De Groot et al. (1997). In the stage 4 mushroom the morphologically distinct tissues that are used for analysis of spatial expression patterns of hypA and hyp $B$ are indicated. Abbreviations: ba, stipe basis; mi, mld-stipe; tz, transitional zone; an, annulus; gi, gills; ic, inner cap; pv, partial veil; pi, pileipellis; $c z$, connecting zone.
\end{abstract}

ristics, a division into class I and class II hydrophobins was made (Wessels, 1994). The hydrophobicity pattern of HYPB is very similar to that of HYPA, Sc $3 p$ and the other class I hydrophobins (Fig. 1a).

By comparison with protein database sequences we found that the polypeptide translated from $b y p B$ has significant homology with only some of the other class I hydrophobins. The highest levels of sequence identity with HYPB were found for hydrophobins of three other basidiomycetes: Sc3p of S. commune, HydPt-1 of the ectomycorrhizal fungus Pisolithus tinctorius and $\mathrm{CoH} 1$ of Coprinus cinereus. When the cysteine residues are used as fixed coordinates in an alignment, the remaining amino acids can be aligned in such a way that they show $37-39 \%$ identity (Fig. 1b). Excluding the eight cysteine residues, the previously isolated $A$. bisporus hydrophobins HYPA, HYPC and ABH3 show only $25-31 \%$ identity with HYPB.

A genomic library of the homokaryotic strain $\mathrm{H} 39$ was then screened. Southern analysis of isolated $\lambda$ clones and genomic DNA resulted in the restriction map presented in Fig. 2. Comparison of the genomic sequence with the sequence of the cDNA clone showed that the hypB ORF is interrupted by two intervening sequences of 79 and $71 \mathrm{bp}$ with normal splice junctions. The sequence surrounding the start codon conforms to the consensus sequence for translation initiation of highly expressed genes (Kozak, 1989). The transcriptional start of bypB was determined by primer extension analysis using RNA isolated from pin stage mushrooms as template. The major transcription start point in this tissue is located at position -97 relative to the inferred start codon and a minor start point was found further upstream at position -296. Fifty-three base pairs downstream of the stop codon the transcript ends in a poly(A) tail and this site is preceded by an AT-rich sequence, which is often found in eukaryotic genes (Humphrey \& Proudfoot, 1988). In the hypB promoter there is a TATA-box (Bucher, 1990), starting $33 \mathrm{bp}$ upstream of the major transcription initiation site.

A number of gene duplications have been found in $A$. bisporus genes (Harmsen et al., 1992; De Groot et al., 1996; Van de Rhee et al., 1996; Smith et al., 1998) and in all cases the duplicated copies are immediately adjacent and in the same orientation. This led us to analyse the regions surrounding bypB by hybridization and sequence analysis. A second copy of $h y p B$ was not found in the $A$. bisporus genome. However, $2.5 \mathrm{~kb}$ upstream of hypB a large ORF was found (Fig. 2) and a cDNA corresponding to this ORF was isolated. Analysis of this cDNA suggests that it encodes the $\mathrm{Fe}-\mathrm{S}$ protein subunit of succinate dehydrogenase, as there is $85 \%$ sequence identity with the $\mathrm{Fe}-\mathrm{S}$ protein subunit of the oyster mushroom Pleurotus ostreatus (EMBL accession no. $\mathrm{AB} 007361)$ and $74 \%$ identity with the same protein subunit of the basidiomycete yeast Ustilago maydis (Broomfield \& Hargreaves, 1992). We have called this gene sudA. sudA is expressed in vegetatively grown mycelium and thus is regulated independently from bypB (results not shown).

\section{Temporal and spatial expression of hypA and hypB}

The transcriptional regulation of the two fruit-bodyspecific hydrophobin genes was compared by determining the mRNA levels of $h y p A$ and $b y p B$ in total fruit body tissue during development and in various parts of mature mushrooms by Northern analysis. Developing fruit bodies were obtained from a $10 \mathrm{~d}$ flushing cycle using commercial cultivation conditions. Fruit bodies were picked from the first visual appearance of primordia, $5 \mathrm{~d}$ after initiation of fruit body formation, until the mature mushrooms had their typical button-like appearance and exposed their spore-bearing gills by breaking the veil (see Fig. 3 for details). The temporal expression of the two genes normalized to the signal 
(a)

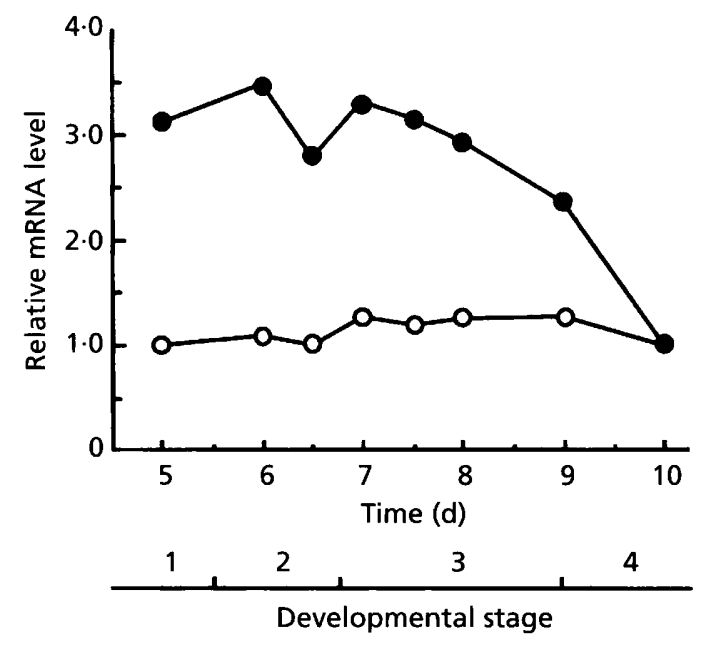

(b)
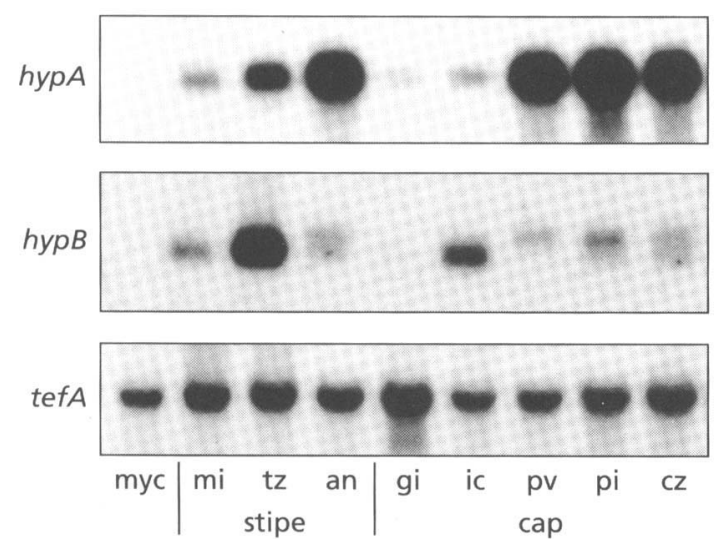

Fig. 4. Northern analysis of the hydrophobin genes in developing fruit bodies. (a) Relative mRNA levels of hypA $(O)$ and $h y p B(O)$ in fruit bodies from day 5 (stage 1 ) to day 10 (stage 4). Relative transcript levels were calculated by normalization against 28S rRNA and the mRNA level obtained for whole stage 4 mushrooms was set to $1 \cdot 0$. (b) Transcript levels of hypA, hyp $B$ and the tefA gene encoding translation elongation factor $1 \alpha$ in different parts isolated from stage 4 mushrooms and in compost-grown mycelium. The abbreviations of Fig. 3 were used and 'myc' denotes compost-grown mycelium. The pv sample contains both partial veil and pileipellis.

obtained by hybridization with a $28 \mathrm{~S}$ rDNA probe (Schaap et al., 1996) during fruit body development is presented in Fig. 4(a). bypA mRNA remains at a more or less constant level during mushroom development and maturation. bypB mRNA levels are highest during the early stages of fruit body development and decrease threefold after $8 \mathrm{~d}$ of development to the levels observed in mature mushrooms.

For determination of the mRNA levels of hypA and hyp $B$ in various parts of mature fruit bodies, caps and stipes of mushrooms were separated and further fractionated (Fig. 3). From caps we isolated the peel (pileipellis), inner cap tissue (plectenchyma), a zone between the pileipellis and the plectenchyma (the connecting zone), partial veil tissue and gill tissue (lamellae). The interconnected tissues of the partial veil and the pileipellis both consist of white hyphae (Umar \& Van Griensven, 1997) and are difficult to separate, making isolation of only partial veil tissue technically difficult. The partial veil sample therefore contained both partial veil and pileipellis tissue. From the stipes, we isolated the annulus as a separate fraction and the stipes were then sectioned horizontally into $3 \mathrm{~mm}$ slices. Of these, three sections were analysed: the transitional zone (or upper part), comprising the physical connection of the stipe with the cap, a mid-stipe section and the stipe basis that connects the mushroom with its mycelial cord. Northern analysis was done with size-fractionated RNA from the various fruit body parts except for RNA from the stipe basis which did not fractionate properly on agarose gels and was therefore analysed by slot blot techniques (not shown).

Fig. 4(b) shows that in mature fruit bodies hypA mRNA accumulates in the annulus, the partial veil, pileipellis tissue and in the zone connecting the pileipellis and the plectenchyma, which is in agreement with previous results (De Groot et al., 1996). The bypA mRNA level in the transitional zone was more than threefold lower, whereas hypA is expressed at relatively low levels in inner cap tissue, in gills and in stipe tissue.

For $\operatorname{byp} B$ the distribution of mRNA in mature mushrooms is completely different. A high concentration of byp $B$ mRNA is found in the transitional zone and an approximately fivefold lower $b y p B$ mRNA level is detected in inner cap tissue. In all other fractions, hyp $B$ mRNA levels were significantly lower than in the transitional zone and the inner cap tissue. In gills, byp $B$ mRNA was below the detection level. Furthermore, within and between assayed fruit body parts, $h y p B$ mRNAs of different sizes are found (Fig. 4b). In accordance with the primer extension experiment, this again indicates that $h y p B$ transcription can start at different positions.

For both hydrophobin genes, no transcripts were found in compost-grown mycelium. The distribution of bypA and hypB mRNAs in mature mushrooms was compared with the expression pattern obtained with tefA encoding translation elongation factor $1 \alpha$. As was found previously (Schaap et al., 1997), tef A shows equal transcript levels in all assayed parts of the fruit body and in vegetative mycelium. This suggests that all assayed fruit body parts are metabolically active.

\section{Spatial expression of hypA and hypB during development}

The previous experiment using conventional Northern analysis techniques showed that in mature mushrooms the highest expression of $b y p B$ is found in the transitional zone. It also shows that $h y p B$ transcription is more prominent during the early stages of development 

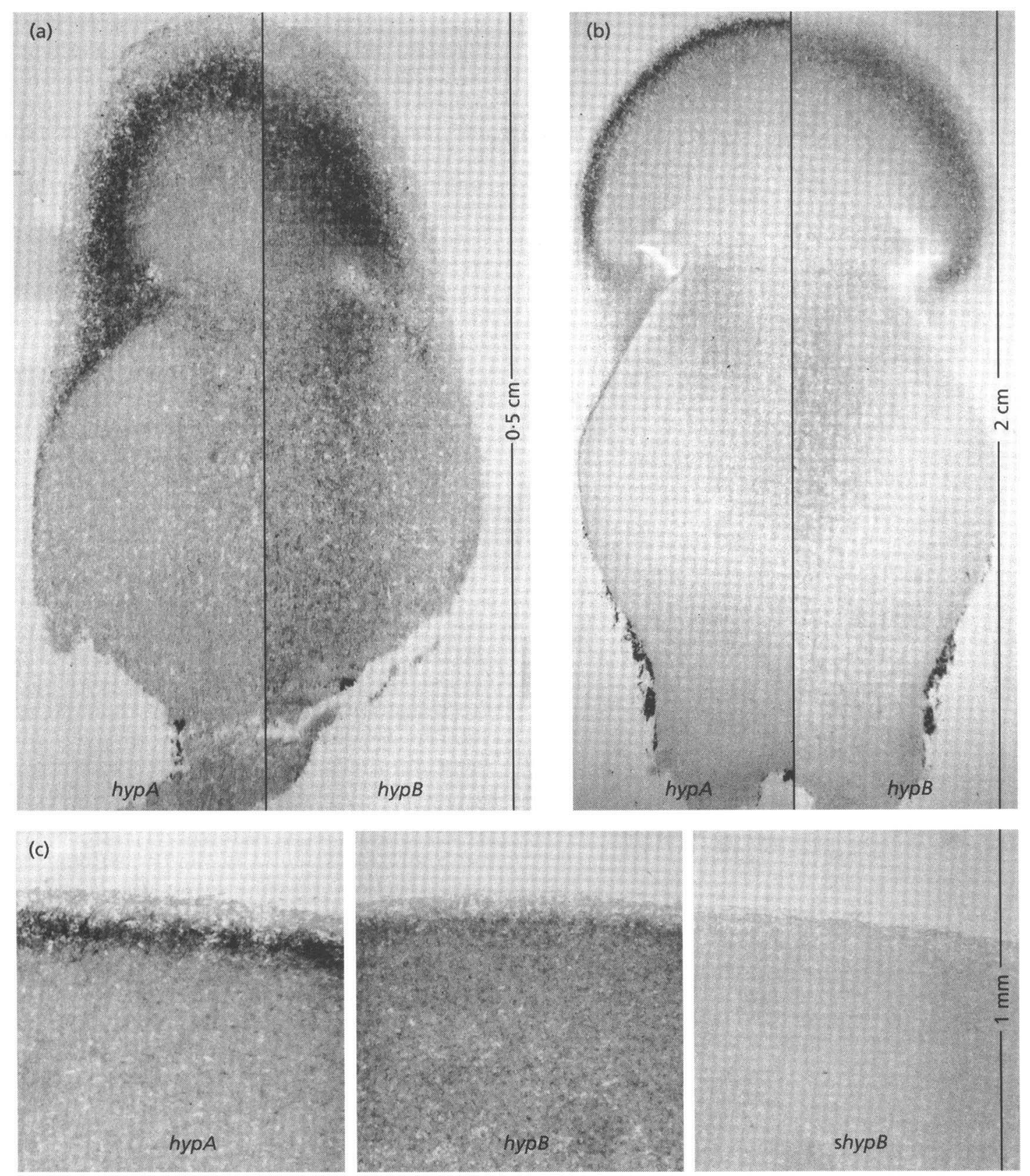

Fig. 5. In situ Northern analysis showing the spatial expression of hypA and hypB during fruit body development. Longitudinal sections of whole fruit body at stage 1 (a) and stage 2 (b) of development. (c) Longitudinal sections of the upper part of the cap of a mature mushroom. Paraffin-embedded fruit body tissues were hybridized with the non-coding strand of hypA and hypB and, as a negative control, with the coding (sense) strand of hypB (shypB).

and declines thereafter. To study the spatial expression of the hydrophobin genes at the early stages of fruit body development we applied in situ hybridization techniques to primordia. Fig. 5(a) shows that with this technique differentiation into cap and stipe tissue can already be observed in pin-shaped primordia that appear $5 \mathrm{~d}$ after initiation of fruit body formation. At this stage of development bypA mRNA can be detected in the universal veil covering the whole primordium. However, the highest bypA mRNA levels are found in the outer regions of future cap tissue. For bypB, the highest mRNA levels are also found in the future cap, but the expression is concentrated in other, more internal cell layers. In the future stipe bypB mRNA is also clearly present in the inner regions but at a lower level, whereas hypA mRNA in the stipe is hardly detectable. As negative controls, primordia slides were probed with the sense strand of hypA and $h y p B$ and no hybridization signals were obtained (not shown). At stage 2, bypA mRNA clearly accumulates in the pileipellis and veil 
hyphae that cover the future cap and the highest $h y p B$ mRNA levels are again found in cells located more internally in the fruit body cap. At stage 4, the mushrooms are too large to be analysed as a whole and we therefore analysed the outer (top) region of a mushroom cap (Fig. 5c). In this region, a thin layer of cells show high expression of bypA, whereas bypB mRNA levels in the outer region of the mushroom cap are low. Again, no signals were found after probing with the sense strands of $b y p A$ and $b y p B$ (Fig. 5c). These results are consistent with the results obtained by the conventional Northern analysis presented in Fig. 4. However, the in situ analysis also demonstrated that the high levels of hypA mRNA in the pileipellis are not produced by the outermost cell layers of the mushroom caps but by cells that are located more internally as can be seen clearly in Fig. 5(a) and (c).

\section{DISCUSSION}

The results presented here show that the gene corresponding to cDNA clone pDG47 belongs to the fungal family of hydrophobin genes. This gene, named $h y p B$, is the third fruit-body-specific hydrophobin-encoding gene that has been found in $A$. bisporus, the other two being the tandemly linked $b y p A$ and $h y p C$ genes (De Groot et al., 1996). In contrast to the expression levels of bypA and $h y p B$, those of bypC are low. The duplicated region comprising hypC is located downstream of hypA and starts 310 bp upstream of the putative translation start of hypC. This indicates that fruit body specificity of transcription is determined by the duplicated promoter region present in both bypC and bypA, whereas an element responsible for the high expression levels of byp $A$ in certain tissues of the fruit body might be located further upstream in the bypA promoter. Comparison of the $b y p A$ and $h y p C$ promoter regions with the $b y p B$ promoter did not reveal similar sequences which could be indicative of regulating elements in these fruit-bodyspecific promoters.

The identification of multiple hydrophobins of $A$. bisporus, of which two are expressed at high levels in fruit bodies, led us to investigate whether these proteins have dissimilar functions. The presence of multiple hydrophobin genes is not unique to A. bisporus but has also been shown for three other basidiomycetes, $S$. commune (Schuren \& Wessels, 1990; Wessels et al., 1995), C. cinereus (Wessels, 1997) and P. tinctorius (Tagu et al., 1996) and the ascomycetes Aspergillus nidulans (Stringer et al., 1991; Stringer \& Timberlake, 1995) and Trichoderma reesei (Nakari-Setälä et al., 1996, 1997). Differences in expression of the hydrophobins of most of these fungi indicate that the different hydrophobins contribute to surface hydrophobicity of morphologically different structures. Although this may be true for all filamentous fungi, especially in the case of the basidiomycetes which often produce large and complex developmental structures, the presence of multiple surface-active hydrophobins seems necessary. For example, of the four hydrophobin-encoding genes discovered in $S$. commune, sc3 was only expressed in vegetatively growing mycelium of both mono- and dikaryons, whereas $s c 1, s c 4$ and $s c 6$ were dikaryonspecific and associated with fruit body formation. Expression patterns obtained with in situ hybridization of the dikaryon-specific genes indicate that regulation of $s c 4$ differs from $s c 1$ and $s c 6$ (Ruiters \& Wessels, 1989). Separate functions were also suggested by the low level of sequence identity between the $S$. commune hydrophobins and from the fact that the secondary mycelium of $s c 3^{-}$deletion strains produced aerial hyphae that were hydrophilic (Van Wetter et al., 1996). The expression patterns observed with Northern analysis of byp $A$ and byp $B$ show that the two genes are differentially regulated in time and space and indicate that each of these A. bisporus hydrophobins has its specific role in development.

The highest transcript levels of bypB are found during the early stages of fruit body development. During these stages the primordium differentiates into a distinctive cap and stipe. Using in situ Northern hybridization techniques it was shown that in primordia the highest levels of bypB mRNA are found in the inner regions of the future cap structure. In mature mushrooms that show a threefold overall decrease in bypB mRNA levels, a strong accumulation of $h y p B$ mRNA was found only in the transitional zone using conventional Northern analysis. These results suggest that the HYPB hydrophobin is instrumental in the differentiation process and that HYPB could be part of a mono- or bilayer that is formed between fruit body caps and stipes. This might relate to the fact that bacterial infections, starting in peel tissue, are often unable to invade the mushroom caps (Umar \& Van Griensven, 1995). Another possibility is that, analogous to the proposed function of the Sc4p hydrophobin of S. commune (Wessels et al., 1995), HYPB is functional in coating air channels in the (stipe of the) fruit body.

bypA mRNA levels during development are more or less constant. At the primordial stage of development, high levels of expression of $b y p A$ are observed in the universal veil covering the whole 'undifferentiated' primordium. In mature fruit bodies, bypA mRNA is mainly found in the pileipellis, the partial veil and the annulus. These fruit body parts consist of so-called white hyphae, which are suggested to represent a lower grade of differentiation than the hyphae of the cap, stipe and gills (Umar \& Van Griensven, 1997).

In a previous paper (De Groot et al., 1996) in which the cloning and regulation of $h y p A$ was described, elevated expression of this gene was also observed in gill tissue. However, the gill fraction used in that paper was probably contaminated with partial veil tissue in which bypA is highly expressed. After improving our method of isolating spore-bearing gills, we have now obtained a purer gill fraction that showed low expression of bypA and no expression of $h y p B$, whereas tef $A$ mRNA levels in gills were equal to the mRNA levels in other parts of mature fruit bodies. Whether this is a general phenom- 
enon in basidiomycetes is unknown. The hydrophobins discovered in the ascomycetes A. nidulans and Neurospora crassa are part of the rodlet layer surrounding conidiospores and contribute to the hydrophobicity of the spore surface. Using a different approach of in situ hybridization on fixed tissue prior to embedding in the glycol methacrylate resin Technovit 7100 , we could analyse expression of $h y p A$ in gill tissue. In preliminary experiments, we detected bypA mRNA only in subhymenial cells (results not shown), which could indicate that these cells produce HYPA monomers that may be part of a hydrophobic layer surrounding the basidiospores. However, it should be noted that Lugones et al. (1996) found that the only fruit body part that was completely unreactive to anti-ABH1/HYPA were the gills which also contain (immature) spores.

The in situ Northern analysis also showed that the bypA mRNA levels in the outermost layer of hyphae are low compared to cell layers located more internally (Fig. 5a, c). When the longitudinal sections were stained for total RNA content of the various cell layers, the outermost layer of hyphae showed less staining than the more internally located cell layers (R. T. P. Roeven, unpublished results) and this suggests that these cells are simply less active. It has been shown that the HYPA rodlet layer is the outermost stratum of the fruit body pileipellis (Lugones et al., 1996). If we assume a direct correlation between hypA mRNA and HYPA protein expression, this implies that the HYPA hydrophobin is mainly produced by these inner layers of hyphae and selfassembly of HYPA monomers does not take place before these molecules have reached the interface between the mushroom surface and the air. This supports the idea that in vivo HYPA specifically selfassembles at hydrophobic-hydrophilic interfaces. In agreement with these results, hot-SDS-resistant HYPA layers are formed when aqueous solutions of purified HYPA monomers are brought into contact with hydrophobic surfaces (Lugones et al., 1996; Gunning et al., 1998) and this behaviour is similar to the interfacial self-assembly observed for Sc3p (Wösten et al., 1993, $1994 a, b)$.

\section{ACKNOWLEDGEMENTS}

The authors thank Drs J. Baars and A. Sonnenberg of the Mushroom Experimental Station for their expertise in culturing the A. bisporus strains and for fruitful discussions.

\section{REFERENCES}

Bochenek, B. \& Hirsch, A. M. (1990). In-situ hybridisation of nodulin mRNAs in root nodules using non-radioactive probes. Plant Mol Biol Rep 8, 237-248.

Broomfield, P. L. E. \& Hargreaves, J. A. (1992). A single aminoacid change in the iron-sulphur protein subunit of succinate dehydrogenase confers resistance to carboxin in Ustilago maydis. Curr Genet 22, 117-121.

Bucher, P. (1990). Weight matrix descriptions of four eukaryotic RNA polymerase II promoter elements derived from 502 unrelated promoter sequences. J Mol Biol 212, 563-578.
Calzone, F. J., Britten, R. J. \& Davidson, E. H. (1987). Mapping of gene transcripts by nuclease protection assays and cDNA primer extension. Methods Enzymol 152, 611-632.

De Graaff, L. H., Van den Broek, H. \& Visser, J. (1988). Isolation and expression of the Aspergillus nidulans pyruvate kinase gene. Curr Genet 11, 499-503.

De Groot, P. W. J., Schaap, P. J., Sonnenberg, A. S. M., Visser, J. \& Van Griensven, L. J. L. D. (1996). The Agaricus bisporus bypA gene encodes a hydrophobin and specifically accumulates in peel tissue of mushroom caps during fruit body development. $J \mathrm{Mol}$ Biol 257, 1008-1018.

De Groot, P. W. J., Schaap, P. J., Van Griensven, L. J. L. D. \& Visser, J. (1997). Isolation of developmentally regulated genes from the edible mushroom Agaricus bisporus. Microbiology 143, 1993-2001.

Devereux, J., Haeberli, P. \& Smithies, O. (1984). A comprehensive set of sequence analysis programs for the VAX. Nucleic Acids Res 12, 387-395.

De Vocht, M. L., Scholtmeijer, K., van der Vegte, E. W., de Vries, O. M. H., Sonveaux, N., Wösten, H. A. B., Ruysschaert, J. M., Hadziioannou, G., Wessels, J. G. H. \& Robillard, G. T. (1998). Structural characterization of the hydrophobin SC3, as a monomer and after self-assembly at hydrophobic/hydrophilic interfaces. Biophys J 74, 2059-2068.

Feinberg, A. P. \& Vogelstein, B. (1983). A technique for radiolabeling DNA restriction endonuclease fragments to high specific activity. Anal Biochem 132, 6-13.

Flegg, P. B. \& Wood, D. A. (1985). Growth and fruiting. In The Biology and Technology of the Cultivated Mushroom, pp. 141-177. Edited by P. B. Flegg, D. M. Spencer \& D. A. Wood. Chichester: Wiley.

Gunning, A. P., De Groot, P. W. J., Visser, J. \& Morris, V. J. (1998). Atomic Force Microscopy of a hydrophobin protein from the edible mushroom Agaricus bisporus. J Colloid Interface Sci 201, 118-126.

Harmsen, M. C., Schuren, F. H. J., Moukha, S. M., Van Zuilen, C. M., Punt, P. J. \& Wessels, J. G. H. (1992). Sequence analysis of glyceraldehyde-3-phosphate dehydrogenase genes from the basidiomycetes Schizophyllum commune, Phanerochaete chrysosporium and Agaricus bisporus. Curr Genet 22, 447-454.

Humphrey, T. \& Proudfoot, N. J. (1988). A beginning to the biochemistry of polyadenylation. Trends Genet 4, 243-245.

Kozak, M. (1989). The scanning model for translation: An update. $J$ Cell Biol 108, 229-241.

Kyte, J. \& Doolittle, R. F. (1982). A simple method for displaying the hydropathic character of a protein. J Mol Biol 157, 105-132.

Lugones, L. G., Bosscher, J. S., Scholtmeyer, K., De Vries, O. M. H. \& Wessels, J. G. H. (1996). An abundant hydrophobin (ABH1) forms hydrophobic rodlet layers in Agaricus bisporus fruiting bodies. Microbiology 142, 1321-1329.

Lugones, L. G., Wösten, H. A. B. \& Wessels, J. G. H. (1998). A hydrophobin $(\mathrm{ABH} 3)$ specifically secreted by vegetatively growing hyphae of Agaricus bisporus (common white button mushroom). Microbiology 144, 2345-2353.

Marck, C. (1988). 'DNA Strider': A 'C' program for the fast analysis of DNA and protein sequences for the Apple Macintosh family of computers. Nucleic Acids Res 16, 1829-1836.

Nakari-Setälä, T., Aro, N., Kalkkinen, N., Alatalo, E. \& Penttilä, M. (1996). Genetic and biochemical characterisation of the Trichoderma reesei hydrophobin HFB1. Eur J Biochem 235, 248-255.

Nakari-Setälä, T., Aro, N., Ilmén, M., Muñoz, G., Kalkkinen, N. \& Penttilä, M. (1997). Differential expression of the vegetative and 
spore-bound hydrophobins of Trichoderma reesei. Eur J Biochem 248, 415-423.

Nielsen, H., Engelbrecht, J., Brunak, S. \& Von Heijne, G. (1997). Identification of prokaryotic and eukaryotic signal peptides and prediction of their cleavage sites. Protein Eng 10, 1-6.

Ruiters, M. H. J. \& Wessels, J. G. H. (1989). In situ localisation of specific RNAs in whole fruiting colonies of Schizopbyllum commune. J Gen Microbiol 135, 1747-1754.

Sambrook, J., Fritsch, E. F. \& Maniatis, T. (1989). Molecular Cloning: a Laboratory Manual, 2nd edn. Cold Spring Harbor, NY: Cold Spring Harbor Laboratory.

Sanger, F., Nicklen, S. \& Coulson, A. R. (1977). DNA sequencing with chain-terminating inhibitors. Proc Natl Acad Sci USA 74, 5463-5467.

Schaap, P. J., Müller, Y., Baars, J. J. P., Op den Camp, H. J. M., Sonnenberg, A. S. M., Van Griensven, L. J. L. D. \& Visser, J. (1996). Nucleotide sequence and expression of the gene encoding $\mathrm{NADP}^{+}$-dependent glutamate dehydrogenase ( $g d h A$ ) from Agaricus bisporus. Mol Gen Genet 250, 339-347.

Schaap, P. J., Müller, Y., Sonnenberg, A. S. M., Van Griensven, L. J. L. D. \& Visser, J. (1997). The Agaricus bisporus pruA gene encodes a cytosolic $\Delta^{1}$-pyrroline-5-carboxylate dehydrogenase which is expressed in fruit bodies but not in gill tissue. Appl Environ Microbiol 63, 57-62.

Schuren, F. H. J. \& Wessels, J. G. H. (1990). Two genes specifically expressed in fruiting dikaryons of Schizophyllum commune: homologies with a gene not regulated by mating-type genes. Gene 90, 199-205.

Smith, M., Shnyreva, A., Wood, D. A. \& Thurston, C. F. (1998). Tandem organization and highly disparate expression of the two laccase genes $l c c 1$ and $l c c 2$ in the cultivated mushroom Agaricus bisporus. Microbiology 144, 1063-1069.

Sonnenberg, A. S. M., Wessels, J. G. H. \& Van Griensven, L. J. L. D. (1988). An efficient protoplasting/regeneration system for Agaricus bisporus and Agaricus bitorquis. Curr Microbiol 17, 285-291.

Stringer, M. A. \& Timberlake, W. E. (1995). dewA encodes a fungal hydrophobin component of the Aspergillus spore wall. Mol Microbiol 16, 33-44.

Stringer, M. A., Dean, R. A., Sewall, T. C. \& Timberlake, W. E. (1991). Rodletless, a new Aspergillus developmental mutant induced by directed gene inactivation. Genes Dev 5, 1161-1171.

Tagu, D., Nasse, B. \& Martin, F. (1996). Cloning and characterisation of hydrophobin-encoding cDNAs from the ectomycorrhizal basidiomycete Pisolithus tinctorius. Gene 168, 93-97.
Umar, M. H. \& Van Griensven, L. J. L. D. (1995). Morphology of Agaricus bisporus in health and disease. Mushroom Sci 14, 103-109.

Umar, M. H. \& Van Griensven, L. J. L. D. (1997). Hyphal regeneration and histogenesis in Agaricus bisporus. Mycol Res 101, 1025-1032.

Van de Rhee, M. D., Mendes, O., Werten, M. W. T., Huizing, H. J. \& Mooibroek, H. (1996). Highly efficient homologous integration via tandem exo- $\beta$-1,3-glucanase genes in the common mushroom, Agaricus bisporus. Curr Genet 30, 166-173.

Van Gils, J. J. (1988). Cultivation. In The Cultivation of Mushrooms, pp. 263-308. Edited by L. J. L. D. Van Griensven. Rustington: Darlington Mushroom Laboratories.

Van Wetter, M. A., Schuren, F. H. J., Schuurs, T. A. \& Wessels, J. G. H. (1996). Targeted mutation of the SC3 hydrophobin gene of Schizophyllum commune affects formation of aerial hyphae. FEMS Microbiol Lett 140, 265-269.

Wessels, J. G. H. (1994). Developmental regulation of fungal cell wall formation. Annu Rev Phytopathol 32, 413-437.

Wessels, J. G. H. (1997). Hydrophobins: proteins that change the nature of the fungal surface. Adv Microb Physiol 38, 1-45.

Wessels, J. G. H., Asgeirsdóttir, S. A., Birkenkamp, K. U., De Vries, O. M. H., Lugones, L. G., Scheer, J. M. J., Schuren, F. H. J., Schuurs, T. A., Van Wetter, M. A. \& Wösten, H. A. B. (1995). Genetic regulation of emergent growth in Schizophyllum commune. Can J Bot 73, S273-S281.

Wösten, H. A. B., De Vries, O. M. H. \& Wessels, J. G. H. (1993). Interfacial self-assembly of a fungal hydrophobin into a hydrophobic rodlet layer. Plant Cell 5, 1567-1574.

Wösten, H. A. B., Asgeirsdóttir, S. A., Krook, J. H., Drenth, J. H. H. \& Wessels, J. G. H. (1994a). The fungal hydrophobin Sc3p self assembles at the surface of aerial hyphae as a protein membrane constituting the hydrophobic rodlet layer. Eur J Cell Biol 63, 122-129.

Wösten, H. A. B., Schuren, F. H. J. \& Wessels, J. G. H. (1994b). Interfacial self-assembly of a hydrophobin into an amphipathic protein membrane mediates fungal attachment to hydrophobic surfaces. EMBO J 13, 5848-5854.

Yanisch-Perron, C., Vieira, J. \& Messing, J. (1985). Improved M13 phage cloning vectors and host strains: nucleotide sequences of the M13mp18 and pUC19 vectors. Gene 33, 103-119.

Received 28 September 1998; revised 4 December 1998; accepted 2 February 1999. 